Proceedings

\title{
Ground-Based GNSS Monitoring of Ionosphere as Implementation of Internet of Things Technology ${ }^{\dagger}$
}

\author{
Olga Lazareva * and Vladimir Chukin \\ Russian State Hydrometeorological University, Malookhtinsky prospect 98, Saint Petersburg 195196, Russia; \\ chukin@meteolab.ru \\ * Correspondence: lazareva@meteolab.ru; Tel.: +7-952-238-2524 \\ + Presented at the 2nd International Electronic Conference on Atmospheric Sciences, 16-31 July 2017; \\ Available online: http://sciforum.net/conference/ecas2017.
}

Published: 17 July 2017

\begin{abstract}
Nowadays, the Internet of Things (IoT) is a rapidly growing technology that allows to integrate digital devices into a network. Using the IoT technology to collect information from a variety of Internet connected GNSS receivers provides a unique opportunity to obtain real-time information about the special and temporal distribution of ionospheric characteristics with high resolution. The ability to create a dense sensor network is achieved through the usage of cheap single-frequency GNSS receivers based on the Arduino technology. This approach can be implemented to obtain real-time data on the total electron content (TEC) of the ionosphere. The determination of the ionospheric delay of the radio signal of GLONASS/GPS satellite and the calculation of the ionospheric TEC are carried out directly in the GNSS receiver. The results are transmitted over a wireless communication channel via Internet to a cloud server, where maps of the TEC of the ionosphere are constructed.
\end{abstract}

Keywords: GNSS; GLONASS; GPS; ionosphere; receiver; Internet of Things

\section{Introduction}

The emergence and development of the remote sensing method has significantly increased the amount of information received about processes occurring in the ionosphere and has opened up new areas of research for scientists. One of the characteristics of the ionosphere is the total electronic content (TEC). The change in TEC signals various processes occurring in the ionosphere and are reflected in subsequent surface events. Method of monitoring the ionosphere is based on the use of ground-based registration of radio signals by the global navigation satellite system (GNSS) [1] and subsequent determination of the TEC of the ionosphere based on the processing of code and phase measurements of radio signal delay [2].

\section{Experiments}

\subsection{Methods}

The determination of the ionospheric TEC by a single-frequency navigation receiver is based on the processing of code and phase pseudorange measurements on the same carrier frequency. The method is based on finding the difference between two successive measurements of pseudoranges, measured by the code and phase of the carrier frequency of the radio signal $[3,4]$ :

$$
\Delta P_{k}-\Delta L k=80.8 f^{2}\left[m_{\mathrm{i}}\left(\beta_{\mathrm{k}}\right)-m_{\mathrm{i}}\left(\beta_{\mathrm{k}-1}\right)\right] T E C_{k}+\varepsilon,
$$


here $\Delta P_{k}-\Delta L_{k}$-is the increment of pseudoranges measured by distance-ranging code and carrier phase; TEC-total electron content of the ionosphere; $f$-frequency of the radio signal; $\left[m_{\mathrm{i}}\left(\beta_{\mathrm{k}}\right)-\right.$ $\left.m_{\mathrm{i}}\left(\beta_{\mathrm{k}-1}\right)\right]$ - the difference of the mapping functions (designed to recalculate the vertical signal delay into an slant delay).

The mapping function can be found from [3]:

$$
m_{\mathrm{i}}\left(\beta_{\mathrm{k}}\right)=\left\{1-\left[R \cos \beta_{\mathrm{k}} /\left(R+Z_{\max }\right)\right]^{2}\right\}^{-0.5}
$$

here $R$ is the average radius of the Earth, equals to 6,371,221 m; $Z_{\max }$ is the height of the maximum of the electron content in the ionosphere, equals to $432,500 \mathrm{~m}$.

The results of calculating the values of the total electron content of the ionosphere contain noise whose values exceed the values of the TEC. To isolate a useful signal and eliminate noise, it is advisable to apply filtering. In this case, the Kalman filter was used, which is based on the principle of continuous recursive correction of measurements as they arrive [5]:

$$
\begin{gathered}
T E C_{k}=T E C_{k-1}+K_{k}\left(\Delta P_{k}-\Delta L_{k}-H_{k} T E C_{k-1}\right), \\
K_{k}=p_{k} H_{k} / \sigma^{2} y_{\prime} \\
H_{k}=80.8 f^{2}\left[m_{\mathrm{i}}\left(\beta_{\mathrm{k}}\right)-m_{\mathrm{i}}\left(\beta_{\mathrm{k}-1}\right)\right], \\
p_{k}=\left[p_{k-1}+\sigma^{2} x\right] /\left[1+\left(p_{k-1}+\sigma^{2} x\right) H^{2} \sigma^{-2} y\right] .
\end{gathered}
$$

\subsection{Technologies}

To create special low-cost devices for implementaion single-frequency method of ionospheric TEC monitoring is possible with the help of the Arduino technology. This is an open programmable hardware platform based on the use of printed circuit boards with a microcontroller. To create a ground-based receiver, a GNSS module is connected to the card that has access to the Internet via a wireless WiFi network. The determination of the ionospheric delay of the radio signal and the calculation of the ionospheric TEC are carried out directly in the GNSS receiver.

Recently, the technology of "Internet of Things" (IoT) is actively developing. IoT is a reliable network of devices, with built-in electronics, software and sensors. IoT technology allows one to transmit TEC data over a wireless communication channel, independently process them without requiring human help.

\section{Results}

\subsection{Kalman Filtering}

In the case of processing the total electron content of the ionosphere, the Kalman filter takes into account errors in the accuracy of measurements of the range to the receiver and the variability of the values of the TEC, minimizing the RMS measurement error. Figure 1a shows the distribution of the total electron content as a function of time. Figure $1 b$ shows a graph of the change in the TEC of the ionosphere over time, which has been filtered by Kalman using a standard mathematical apparatus.

\subsection{IoT Device for TEC Monitoring}

The developed GNSS receiver prototype consists of a microcontroller ESP8266 and a U-blox NEO-M8 module. The module design allows to register binary data of code and phase measurements at frequency $1575.42 \mathrm{MHz}$ in the UBX format. Connection to the Internet is via a WiFi wireless connection to the nearest access point. The module is powered by a $5 \mathrm{~V}$ power supply. Topcon GB1000 receiver was also used in our experiments. 


\section{Discussion}

The main task of GNSS is the determination of the coordinates of the receiver processing radio signals from navigational satellites [6,7]. The full deployment of GNSS and the improvement of algorithms for solving inverse problems of remote sensing significantly improved the methods for determining ionospheric parameters. Global monitoring helps to keep a record of the current state of the ionosphere $[8,9]$.

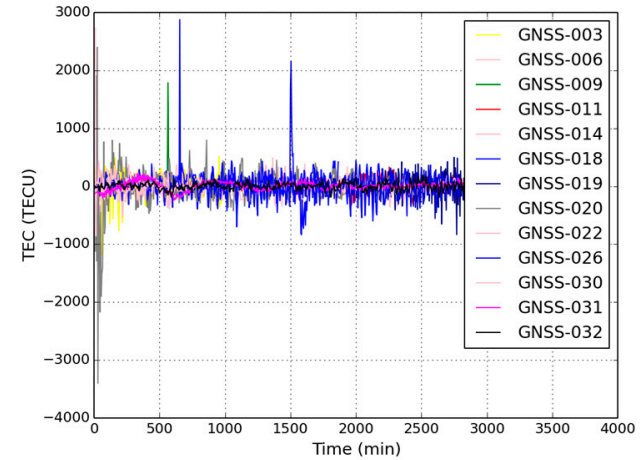

(a)

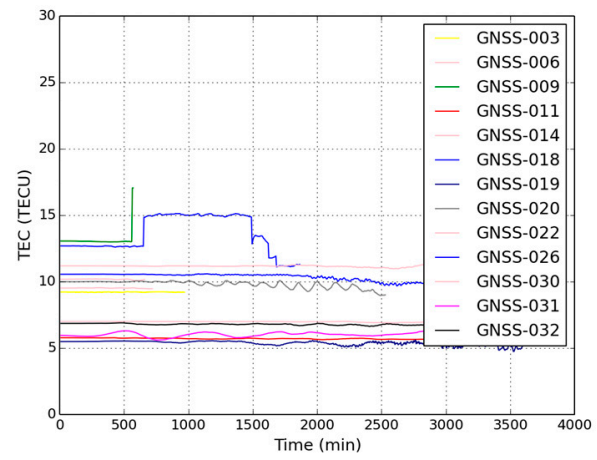

(b)

Figure 1. Results of TEC measurements by single-frequency method: (a) Before Kalman filtering; (b) After Kalman filtering.

The use of technology IoT to gather information from multiple GNSS receivers connected to the Internet, gives one the unique opportunity to obtain operational information about the distribution of TEC with high spatial resolution. The ability to create a dense measuring network is achieved through the creation of cheap GNSS receivers. The determination of the ionospheric delay of the radio signal and the calculation of the ionospheric TEC are carried out directly in the GNSS receiver. The results are transmitted over a wireless communication channel through the global Internet to a dedicated server, where maps of the TEC of the ionosphere.

\section{Conclusions}

The use of technology IoT to gather information from multiple GNSS receivers connected to the Internet, gives one the unique opportunity to obtain operational information about the distribution of TEC with high spatial resolution. The results are transmitted over a wireless communication channel through the Internet to a cloud service, where maps of the TEC of the ionosphere can be constructed.

Author Contributions: O.L. and V.C. conceived and designed the experiments; O.L. performed the experiments; O.L. and V.C. analyzed the data; O.L. and V.C. contributed analysis tools; O.L. wrote the paper.

Conflicts of Interest: The authors declare no conflict of interest.

\section{Abbreviations}

The following abbreviations are used in this manuscript:

$\begin{array}{ll}\text { TEC } & \text { Total Electron Content } \\ \text { IoT } & \text { Internet of Things } \\ \text { GNSS } & \text { Global Navigation Satellite System } \\ \text { GPS } & \text { General Positioning System } \\ \text { GLONASS } & \text { GLObal NAvigation Satellite System }\end{array}$




\section{References}

1. Zolotov, O.V.; Namgaladze, A.A.; Prokhorov, B.E. Specific features of ionospheric total electron content variations in the periods of preparation of the earthquakes on March 11, 2011 (Japan) and October 23, 2011 (Turkey). Russ. J. Phys. Chem. 2013, 5, 599-605.

2. Zhou, Y.; Wu, Y.; Qiao, X.; Zhang, X. Ionospheric anomalies detected by ground-based GPS before the Mw7.9 Wenchuan earthquake of May 12, 2008, China. J. Atmos. Sol. Terr. Phys. 2009, 71, 959-966, doi:10.1016/j.jastp.2009.03.024.

3. Kazantsev, Y.M.; Fateev, Y.L. Determination of the ionospheric error in the pseudorange measurement of single frequency equipment of the GLONASS and GPS systems. J. Radioelectron. 2002, 12. Available online: http://jre.cplire.ru/mac/dec02/6/text.html (accessed on 31 May 2017).

4. Ionospheric Correction Algorithm for Galileo Single Frequency Users. European GNSS (Galileo) Open Service-European Commission. 2016. Available online: https://www.gsceuropa.eu/system/files/galileo_documents/Galileo_Ionospheric_Model.pdf (accessed on 27 May 2017).

5. Meteolab. Available online: http://meteolab.ru/ru/presentation/2013-11-07.pdf (accessed on 31 May 2017).

6. Tereshchenko, E.D.; Milichenko, A.N.; Shvets, M.V.; Chernyakov, S.M.; Korableva, I.V. Total Electron Content Estimation Using Satellites Signals of the Global Navigation System GLONASS. Herald of Kola Science Centre of the Russian Academy of Sciences 2015, 1, 32-44. Available online: http://www.kolasc.net.ru/russian/news/vestnik/vestnik-1-2015.pdf (accessed on 21 September 2017)

7. Kunitsyn, V.E.; Tereshchenko, E.D.; Andreeva, E.S. Satellite radio probing and radio tomography of the ionosphere Radiotomogr. Ionos. 2007, 336, doi:10.3367/UFNr.0180.201005k.0548.

8. Demenok, P.V.; Deineko, V.N.; Flerko, S.N.; Shigimaga, N. Method of recovery of the ionospheric delay signals based on the combined use of code and phase GPS measurements. Inf. Process. Syst. 2004, 42. Available online: www.hups.mil.gov.ua/periodic-app/article/4561/soi_2005_2_6.pdf (accessed on 17 May 2017).

9. Afifi, A.; El-Rabbany, A. Single Frequency Precise Point Positioning Using GPS and Galileo Observables, FIG Congress, Enhancing the Relevance Kuala Lumpur, Malaysia. 2014. Available online: https://www.fig.net/resources/proceedings/fig_proceedings/fig2014/papers/ts03b/TS03B_afifi_elrabbany_7286.pdf (accessed on 27 June 2017). 